\section{Are dopamine receptors accessible to intracellularly applied agonist?}

THERE is much evidence that receptors to neurotransmitters are generally on the outer surface of cell membranes ${ }^{1-3}$. The experiments reported here raise the possibility that acinar cells of cockroach salivary glands may be activated intracellularly as well as by extracellularly applied agonists.

Studies were performed using the isolated innervated salivary gland of Nauphoeta cinerea (Olivier) bathed in flowing solution $\left(2 \mathrm{ml} \mathrm{min}^{-1}\right.$ ) containing $(\mathrm{mM}) \mathrm{NaCl}, 160 ; \mathrm{KCl}, 1 ; \mathrm{CaCl}_{2}, 5$; Tris- $\mathrm{HCl} p \mathrm{H} 7.6$ buffer, 5 and mounted as previously described ${ }^{4}$. Cells were impaled with microelectrodes containing agonists in concentrations of up to $1.0 \mathrm{M}$ dissolved in either potassium acetate or $\mathrm{KCl}$. The electrodes were used not only for intracellular recording but also for ejecting the agonist by means of current pulses. The reservoir ducts were drawn into a small suction electrode to allow stimulation of the salivary nerve. Figure $1 a$ shows two successive responses of an acinar cell, $\mathrm{N}$ to a single nerve stimulus and D to the application of a current pulse to the intracellular electrode equivalent to a charge of $40 \mathrm{nC}$. The responses can be seen to be very similar. In Fig. $1 b$ the response to a burst of nerve stimuli, $N$, is followed by three responses to increasing ionophoretic charges and it can be seen that there is a graded relationship between amplitude of response and charge.

Intracellular applications of dopamine were made to about 100 cells and responses were obtained from about two-thirds of these. In a few experiments responses were also obtained from intracellular applications of adrenaline, noradrenaline and 5hydroxytryptamine which, like dopamine, have also been shown to be effective when applied extracellularly ${ }^{5}$.

Two possible explanations for these responses are (1) receptors are activated intracellularly by the ionophoretically applied agonists or (2) the receptors on the outer membrane surface are activated by agonist which has leaked through the membrane. Attempts to distinguish between (1) and (2) have so far been inconclusive. In one experiment we compared the sensitivity of a series of cells to extra- and intracellular application from the same ionophoretic pipette. The cell was first impaled with a separate recording electrode, the ionophoretic pipette was brought as close as possible to the outer surface of the acinus and a response to a pulse of dopamine was elicited. An attempt was

Fig. $1 a$, Lower trace, voltage; upper trace, current passed through recording electrode. $\mathrm{N}$, intracellularly recorded response to a stimulus applied to the salivary nerve; $D$, response to a dopamine pulse ejected by a $100 \mathrm{nA}$ current for $0.4 \mathrm{~s}$. Downward deflection corresponds to hyperpolarisation. The electrode contained $0.7 \mathrm{M}$ dopamine and $1 \mathrm{M}$ potassium acetate. $b$, Intracellular response, $\mathrm{N}$, to a burst of three nerve stimuli followed by responses to three pulses of dopamine ejected from the intracellular electrode by currents of $100 \mathrm{nA}$ for durations of $0.2,0.4$ and $0.6 \mathrm{~s}$ respectively. The electrode contained $0.3 \mathrm{M}$ dopamine and $1 \mathrm{M}$ potassium acetate.

$a$
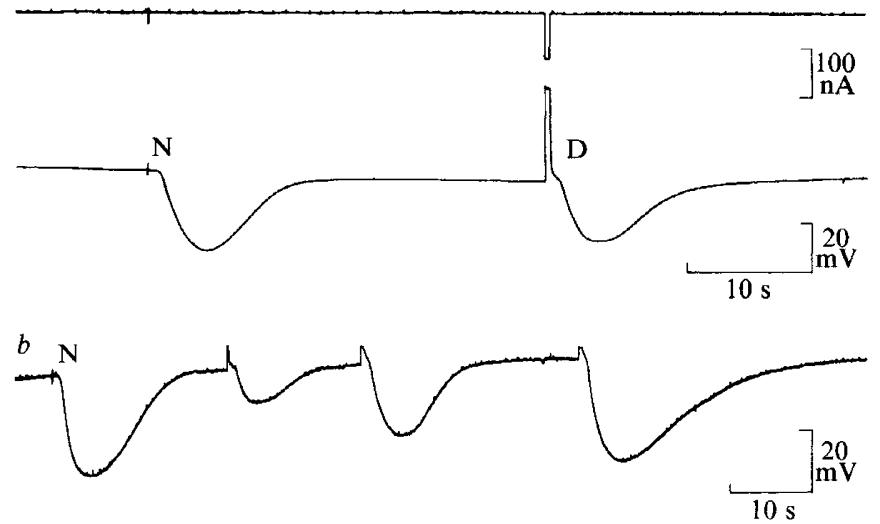

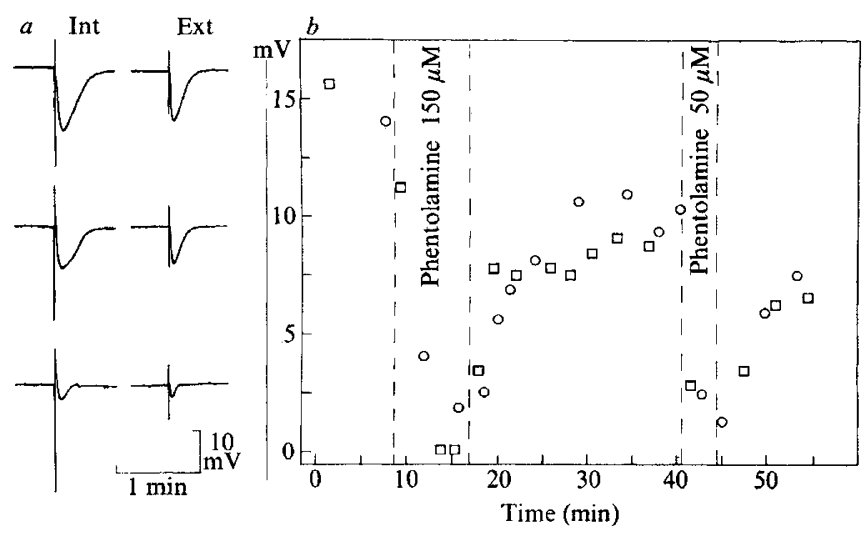

Fig. 2 Effect of phentolamine on intracellularly recorded responses from the same cell. $a$, Int, pulses of dopamine ejected from the intracellular electrode ( $100 \mathrm{nA}$ for $0.4 \mathrm{~s}$ ); Ext, pulses of dopamine ejected from an extracellular pipette $(200 \mathrm{nA}$ for $0.08 \mathrm{~s}$ ). Both electrode and pipette contained $0.5 \mathrm{M}$ dopamine and $3 \mathrm{M}$ potassium acetate. Top records, control; middle records, during recovery from a short exposure to $150 \mu \mathrm{M}$ phentolamine; bottom records, in $25 \mu \mathrm{M}$ phentolamine. $b$, part of time course of experiment from which records in $a$ were taken. $O$, Intracellularly applied dopamine; $\square$, extracellularly applied dopamine.

then made to insert the ionophoretic pipette. The initial recording electrode was usually dislodged in the process but this did not matter because if the cell was successfully impaled with the ionophoretic pipette it could also be used for recording. Little difference was found between the maximum sensitivities with the two different methods of application. For an electrode containing $50 \mathrm{mM}$ dopamine in $3 \mathrm{M}$ potassium acetate the largest value for the ratio of response to ionophoretic charge was $3 \mathrm{mV} \mathrm{nC}^{-1}$ for intracellular and $2.3 \mathrm{mV} \mathrm{nC}^{-1}$ for extracellular application. (If it is assumed that half the current is carried by cations and that the transport number of the dopamine ion is the same as that of $\mathrm{K}^{+}, 1 \mathrm{nC}$ would correspond to the ejection of about $10^{-16} \mathrm{~mol}$; this would give rise to an internal concentration of about $10^{-7} \mathrm{M}$ if the dopamine was uniformly distributed throughout an acinus of the usual diameter of about $100 \mu \mathrm{m}$.) This result might be thought to argue against the leakage hypothesis, (2), but the result of a second type of experiment was found to be consistent with it. Cells were impaled with one ionophoretic pipette for intracellular recording and dopamine application and a second similar pipette was placed close to the acinar surface for extracellular dopamine application. After matching responses were obtained, phentolamine, which is known to antagonise extracellularly applied dopamine $^{5}$, was added to the flowing bathing solution. Responses to both intracellular and extracellular dopamine were reduced to the same extent (Fig. 2); thus the leakage hypothesis cannot be rejected. However, as phentolamine may be able to leak into the acinar cells, the possibility that the receptors might be accessible from both sides of the membrane cannot be excluded.

M.R.M. is an MRC Research Student.

Department of Veterinary Physiology,

C. R. HOUSE

University of Edinburgh,

Summerhall,

Edinburgh, UK

Department of Pharmacology,

B. L. GINSBORG MARY R. MITCHELL

University of Edinburgh,

1, George Square,

Edinburgh, UK

Received 26 June; accepted 29 August 1978.

1. Del Castillo, J. \& Katz, B. J. Physiol., Lond. 128, 157-181 (1955).

2. Reuter, H. J. Physiol., Lond. 242, 429-451 (1974).

3. Iwatsuki, N. \& Petersen, O. H. J. Physiol, Lond. 269, 72.3-733 (1977)

4. Ginsborg, B. L. \& House, C. R. J. Physiol, Lond. 262, 477-487 (1976).

5. Ginsborg, B. L., House, C. R. \& Silinsky, E. M. J. Physiol., Lond. 262, 489-500 (1976) 